\title{
Preparation and microscopic characterization of biobased nanoparticles from natural waste materials
}

\author{
Vijaya K Rangari*, Vitus Apalangya, Manik Biswas, and Shaik Jeelani \\ Department of Materials Science and Engineering, College of engineering, Tuskegee University, \\ Tuskegee, AL 36088, United States
}

In recent years, nanoparticles derived from natural resources have attracted interest of researchers to use them as potential materials for applications in several areas including biomedical and polymer fillers, where synthetic materials are found to be toxic. There is very limited research published in open literature on the conversion of biobased inorganic materials into functional products to meet societal needs. In this research, we present the synthesis of nanoparticles from natural waste, renewable resources, such as eggshells and rice husk. The nanoparticles include in this study are: $\mathrm{CaCO}_{3}$ and Calcium hydroxyapatite (CHA) from eggshell and $\mathrm{SiO}_{2}$, from rice husk. Rice husk ( $\mathrm{RH}$ and eggshells are excellent sources of bio based silica $\left(\mathrm{SiO}_{2}\right)$, and calcium carbonate $\left(\mathrm{CaCO}_{3}\right)$ particles respectively. About 45,000 tons of chicken eggshells are produced annually as a waste [1]. The safe disposal of these eggshells burdens the environment, poultry industry and consumers, financially. Therefore, alternative use of waste eggshell will be obviously a benefit to society. Recently we have developed a simple technique to extract $\mathrm{CaCO}_{3}$ from eggshell and used them as a value-added product [2-5]. Similarly the $\mathrm{RH}$ is a waste byproduct of rice and produces about 20-22\% weight of the total rice production. United States of America alone produced $\sim 13$ billion tons of rice in 2015 [6] and 10.6 million tons of sugar bagasse [7]. RH constitutes $\sim 20 \%$ of silica by weight and usually used ineffectively. Incorporation of these hard particles into a polymer matrix can eventually improve the properties of the polymer and thus also reuse and recycle the waste. These biobased particles are also highly biocompatible and suitable for bone regeneration and other biomedical applications.

In this study the nanoparticles of calcium phosphate were prepared from egg, mussel and quahog shells. These particles were initially cleaned and ball milled to $\sim 20 \mu \mathrm{m}$ size particles. About $10.00 \mathrm{~g}$ of each shell powder was added gently into a $500 \mathrm{ml}$ Erlenmeyer flash containing $13.85 \mathrm{~mL}$ of nitric acid $\mathrm{HNO}_{3}$ and stirred vigorously using a magnetic plate at room temperature for 20 minutes to produce calcium nitrate from calcium carbonate. In the second step, diammonium hydrogen phosphate powder was prepared as follows: $30 \mathrm{ml}$ of ammonium hydroxide (28-30 \%) was transferred into a 125 Erlenmeyer flask to which a stoichiometry amount $(7.3 \mathrm{ml})$ of phosphoric acid $(85 \%$ semiconductor grade) was added to the flask at a rate of $0.5 \mathrm{ml} /$ minute using a micro pipette. The reaction occurred rapidly with the evolution of heat and fumes. The white crystalline particles filtered and washed thoroughly using a mixture of $20 \mathrm{ml}$ of deionized water and ethanol $(1: 1 \mathrm{v} / \mathrm{v})$. In the last step the crystals were washed with $10 \mathrm{ml}$ of $70 \%$ cold ethanol. The crystals were allowed to dry overnight in a vacuum oven at $60^{\circ} \mathrm{C}$. These crystals were used for the next experiment. In the last and third step, an equivalent of $1.50 \mathrm{~g}$ of calcium nitrate prepared in the first step dispersed in water and made up to $50 \mathrm{ml}$ with deionized water in a 250 $\mathrm{ml}$ Erlenmeyer flask. The solution was stirred for 5 minutes at $200 \mathrm{rpm}$ at a controlled temperature of 40 ${ }^{\circ} \mathrm{C}$. A weight of $1.1877 \mathrm{~g}$ of diammonium hydrogen phosphate was dissolved in $30 \mathrm{ml}$ deionized water. The diammonium solution was added dropwise at a rate of $1.5 \mathrm{ml} / \mathrm{min}$ to the calcium nitrate solution. The reaction mixture was stirred for 5 minutes over a magnetic stirring plate at room temperature. The $\mathrm{pH}$ of the solution was adjusted using ammonium hydroxide. The experiment was carried out at $\mathrm{pH}$ of 8 , 
9 and 11. The reaction mixture was then transferred to microwave vessel and microwaved in CEM microwave equipped with a fiber optic probe; the sample was purged with argon gas at a pressure of 60 psi and at a temperature of $80{ }^{\circ} \mathrm{C}$ for 10 minutes. The crystals were collected and washed thoroughly using a mixture of ethanol and deionized water $(1: 1 \mathrm{v} / \mathrm{v})$ and then centrifuged at $1200 \mathrm{rpm}$ for 10 minutes to remove the solvent. This procedure was carried out for the three shells (egg, mussel and quahog shells). These particles were used for further microscopic analysis.
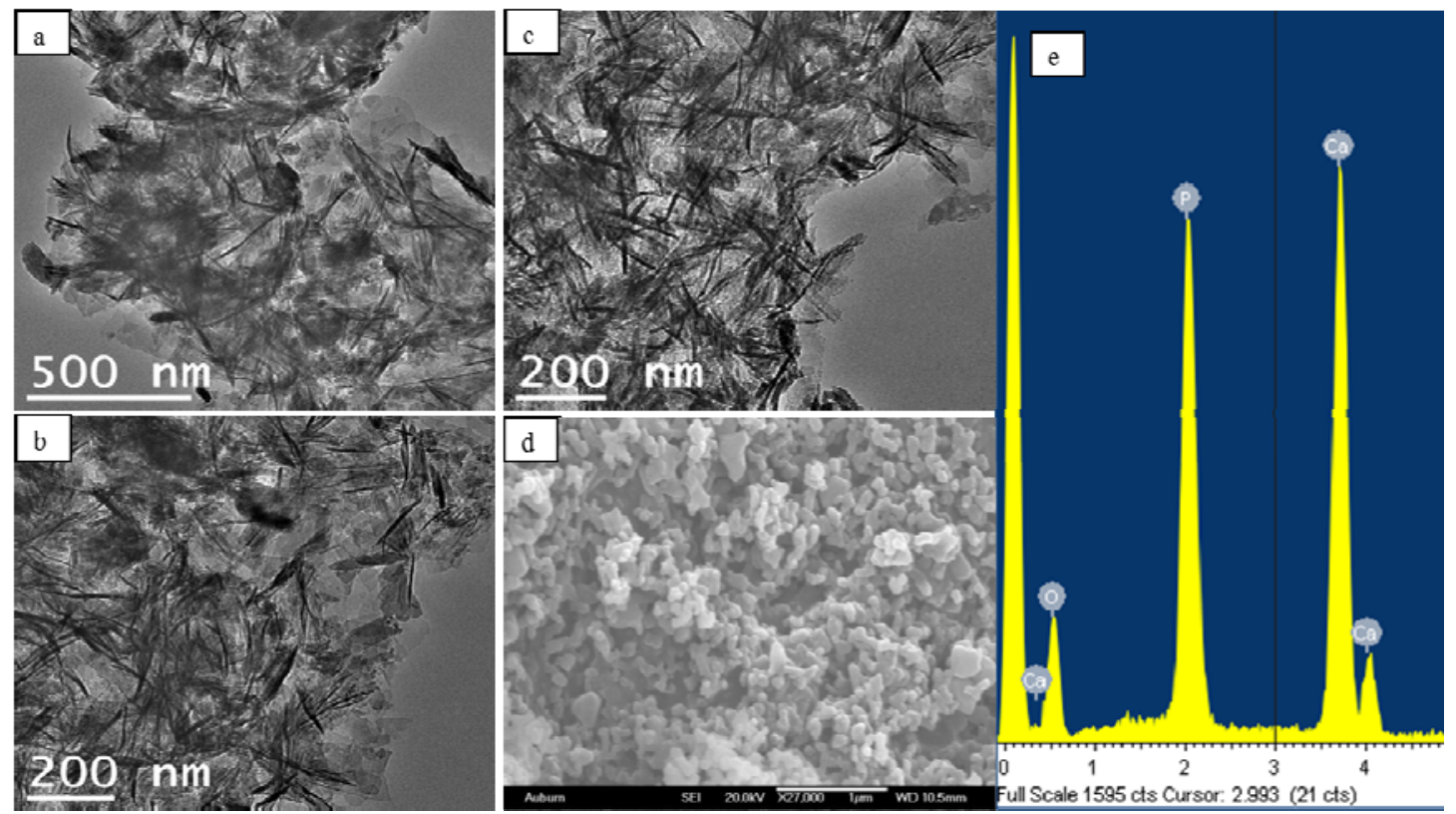

Figure 1 TEM and SEM micrographs of calcium phosphate synthesized from (a) egg (b) mussel (b) quahog (d) rock caco3 (e) EDS spectrum of calcium phosphate from eggshell

References:

[1] H.V.Walton, O.J.Cotteril, J.M.Vandepop, "Composition of shell waste from egg breaking plants”. Poultry Science, Vol 52 No.5, 1973, pp1836-1841

[2] A.H.Tarig, V.K.Rangari and S. Jeelnai."Value added Bio-polymer nanocomposites from waste eggshell based $\mathrm{CaCO}_{3}$ nanoparticles as fillers" ACS Sustainable Chemistry \& Engineering, Vol 2 No.4, 2014, pp706-717.

[3] A.H.Tarig, V.K.Rangari and S. Jeelani, Mechanical and thermal properties of bio-based $\mathrm{CaCO} 3 /$ Soybean based hybrid unsaturated polyester nanocomposites, Journal of Applied Polymer Science, Vol. 30,2013, pp1442-1452 (Cover page article).

[4] M.R.Muhammad, N.N Anil, J.T.Boniface, A. Vitus, V.K. Rangari, "Bio-inspired 'green' nanocomposite using hydroxyapatite synthesized from eggshell waste and soy protein”, Journal of Applied Polymer Science, DOI: 10.1002/app.43477, Vol 133, pp43477 2016.

[5] J.T.Boniface, V.K. Rangari, S.Jeelani, "Effect of Reinforcement of Sustainable $\beta-\mathrm{CaSiO} 3$ Nanoparticles in Bio-based Epoxy Resin System". J. Appl.Polym. Sci. 2014, 131, 40867. DOI: 10.1002/APP.40867

[6] https://www.statista.com/statistics/190823/top-us-states-for-rice-production/

[7] http://www.factfish.com/statistic/bagasse,\%20production 